\title{
A school-based supplementary food programme in rural Kenya did not reduce children's intake at home
}

\author{
Constance A Gewa ${ }^{1, *}$, Suzanne P Murphy², Robert E Weiss ${ }^{3}$ and \\ Charlotte G Neumann ${ }^{4}$ \\ 'Department of Nutrition \& Food Studies, College of Health \& Human Services, George Mason University, \\ 10340 Democracy Lane MSN 1F8, Fairfax, VA 22030, USA: ${ }^{2}$ University of Hawaii Cancer Center, Honolulu, \\ HI, USA: ${ }^{3}$ Department of Biostatistics, School of Public Health, University of California, Los Angeles, CA, USA: \\ ${ }^{4}$ Departments of Community Health Sciences and Pediatrics, Schools of Public Health and Medicine, University \\ of California, Los Angeles, CA, USA
}

Submitted 17 November 2011: Final revision received 9 April 2012: Accepted 30 May 2012: First published online 9 July 2012

\begin{abstract}
Objective: To examine changes in energy intake along with markers of dietary quality (animal-source energy and protein intakes) among household members in the presence of supplementary school feeding in rural Kenya.

Design: A 2-year, longitudinal, randomized controlled feeding intervention study. Setting: Kyeni South Division, Embu District, Kenya.

Subjects: A total of 182 schoolchildren and selected household members.

Results: There was no evidence that schoolchildren who received supplementary snacks at school experienced reduced intakes at home or that intakes by other family members were increased at the expense of the schoolchild's intake. Conclusions: This analysis highlights a number of factors useful in planning for supplementary feeding interventions in rural Kenya and similar communities.
\end{abstract}

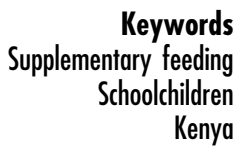

Food distribution and childcare practices that favour particular gender and age groups have been reported among different populations ${ }^{(1-4)}$, but little is known about the effect of participation in supplementary feeding programmes that only target selected household members. A concern has been the likelihood of reallocation of foods/nutrients from programme targets to non-targets within the household. It has been shown that programme foods may be distributed to non-target household members when foods are distributed in the home ${ }^{(5)}$. Relatively few studies have assessed the dietary impact of schoolbased feeding among populations in Africa ${ }^{(6)}$. Studies that have assessed the dietary impact of school-based feeding on programme recipients in India, Bangladesh and the Philippines have shown that the total daily energy intake among target schoolchildren increased by about 75-100\% of the school feeding energy on the days that the children participated in the programme ${ }^{(6-9)}$. However, very few studies have assessed the dietary impact of school-based feeding programmes on non-target household members. Furthermore, a study conducted among African children did not study the impact of school feeding on recipients' diet $^{(10)}$. Reallocation of foods consumed within the home can happen in two possible ways: programme foods may be distributed to non-target household members or nonprogramme foods previously provided to target members may be reallocated to other household members.
In the present analysis we examine changes in the amount of food consumed (total energy intake) and dietary quality (total protein intake, animal-source (AS) energy intake and AS protein intake) among household members in the presence of supplementary feeding of schoolchildren in rural Kenya. The Child Nutrition Project (CNP) provided three types of snacks to schoolchildren (vegetarian, meat and milk snacks), providing an opportunity to assess whether changes in intakes within the household differed by type of snack provided. The snacks were served at 09.00 hours so as not to interfere with the schoolchildren's usual dietary behaviour, and thus we hypothesized that: (i) there would be no statistically significant decreases in either the quantity or quality of food from home sources for schoolchildren in the intervention groups receiving snacks; and (ii) there would be no changes in intakes for other household members in these groups. No changes were expected for any of the household members in the control group.

\section{Materials and methods}

Data were collected as part of the CNP, a group-randomized controlled feeding intervention study carried out in Kyeni South Division of Embu District in Eastern Province, Kenya from 1998 to $2000^{(11)}$. The study area is rural and 
subsistence farming is the primary occupation. All children $(n 554)$ enrolled in grade 1 (median age $7 \cdot 4$ years) from twelve selected primary schools participated in the CNP study. The schools were randomized to one of four snack groups: (i) control (no food supplement provided); (ii) vegetarian supplement (a feeding based on a traditional local dish (githeri) of maize, beans and vegetables); (iii) milk supplement (githeri plus a glass $(250 \mathrm{ml})$ of whole cows' milk); and (iv) meat supplement (githeri cooked with $85 \mathrm{~g}$ of minced beef). The intervention period was 24 months, starting in August 1998 and ending in July 2000. Schools were in session for 3-month terms, with a 1-month holiday between each term with no feeding. Snacks were provided on all school days during the six school terms. The school snacks were approximately isoenergetic and contained an estimated energy content of $\sim 1046 \mathrm{~kJ}$ ( $\sim 250 \mathrm{kcal}$ )/serving during the first school term of the intervention (September to November 1998 ) and $\sim 1339 \mathrm{~kJ}(\sim 320 \mathrm{kcal}) /$ serving thereafter. School snacks were analysed every 3 months to ensure prescribed energy content; micronutrient content was analysed initially and twice annually thereafter. Project-trained feeding assistants served the snacks to the children in their classrooms, collected information on attendance and collected and measured the snack leftovers. All project enumerators and testers were not blinded to the snack group assignments but were blinded to the CNP study hypotheses. The schoolchildren's parents were aware of the snack group assignments. However, they were asked not to alter the children's home intake. An assessment of percentage of school days attended during the study period showed that mean attendance rate was higher among the meat group compared with the vegetarian, milk and control groups with a difference of $2.97 \%, 2 \cdot 78 \%$ and $3 \cdot 93 \%$, respectively ${ }^{(12)}$. Supplement consumption levels were high, with supplements eaten completely in over $99 \%$ of the child-feeding sessions across all snack groups and across all the terms that the snacks were provided ${ }^{(13)}$. A detailed description of the study area and design has been published elsewhere ${ }^{(11)}$.

One of the three schools within each snack group was randomly selected by the project statistician to participate in the intra-household food allocation study, altogether yielding a total of 182 schoolchildren (Fig. 1). The goal was to include the mother, father, schoolchild and a sibling of the schoolchild within the age range of $2-15$ years. There were no siblings within ages $2-15$ years in $13 \%(24 / 182)$ of the households while $17 \%(31 / 182)$ of the fathers worked outside the study area and were not included. Data used for the intra-household food allocation study

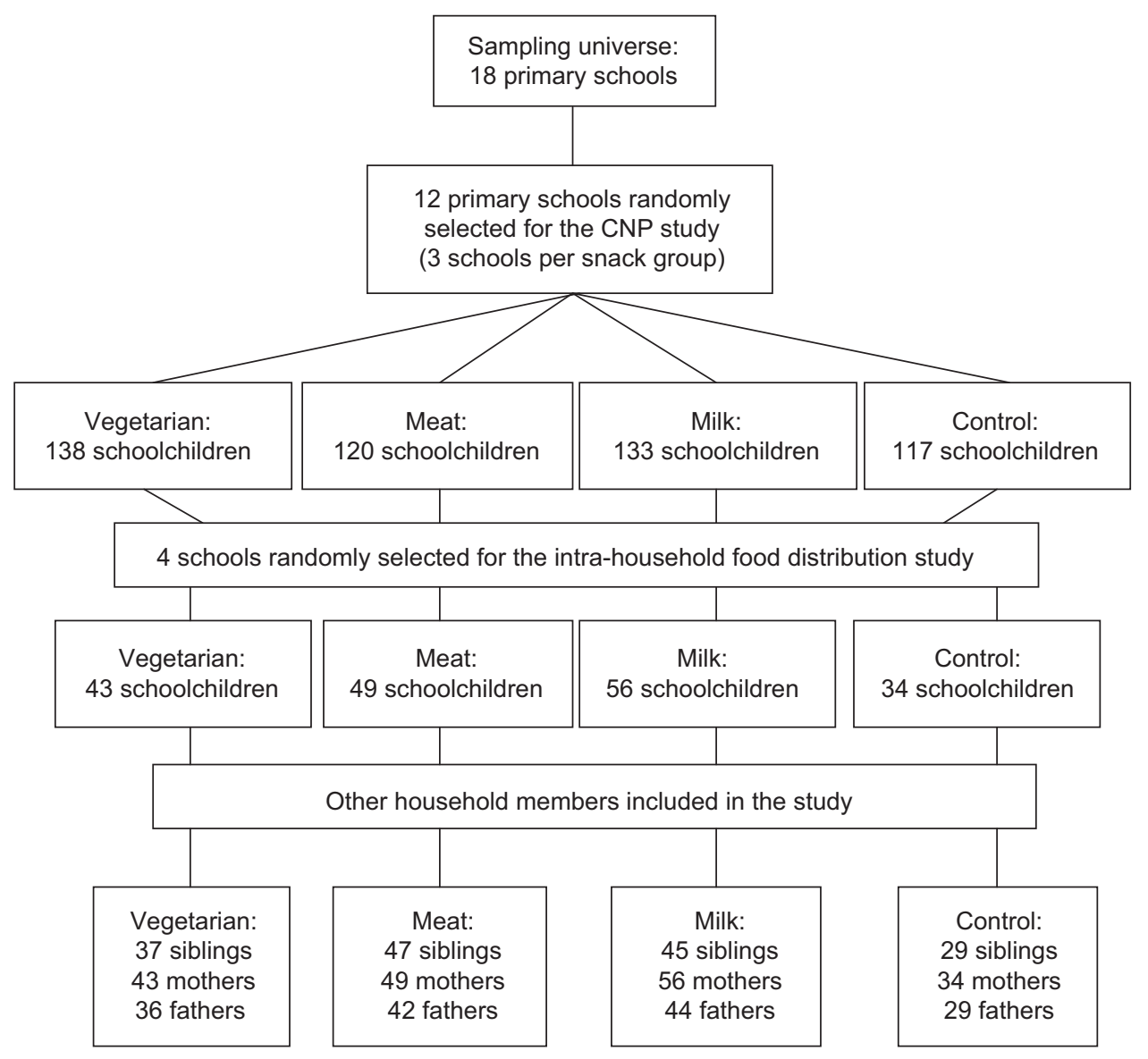

Fig. 1 Flow diagram displaying participants recruited into the intra-household food distribution study 
were collected at baseline in May-August 1998 and two years later in March-May 2000. Human Subjects Approval was obtained for the research study from the University of California, Los Angeles, the University of Nairobi, School of Medicine, Kenya and the Office of the President, Government of Kenya. Local and district authorities helped facilitate implementation of the study. The community was informed in detail about the aim and procedures of the intervention. Informed verbal consent by parents of study children was obtained before the study.

\section{Food intake}

Dietary information consisted of three non-consecutive $24 \mathrm{~h}$ recalls for each of the household members at baseline and again during the follow-up period. Information on daily intake for each of the four household members was obtained, with the mothers being the main respondents. Each respective household member was asked to assist with the interview when present. Women with experience in dietary data collection methods from a previous study ${ }^{(14)}$ were retrained to conduct $24 \mathrm{~h}$ recall interviews at home. The enumerators did not work over the weekend, so the dietary data collected reflect what was consumed on any one day from Sunday to Thursday. Procedures followed in determining nutrient intake have been previously described ${ }^{(15)}$. In summary, mothers were asked to estimate amounts of foods consumed by household members and the ingredients used in mixed dishes prepared in the home. Common portion measures and food models were used, and later converted to gram weights using a database developed for this purpose. Respondents were also asked to describe foods consumed outside the home, including the primary ingredients for any out-of-home mixed dishes. Standard recipes were used to help determine the nutrient intake from these mixed dishes. The standard recipes were based on dietary information that had been collected in a previous study in the same study area ${ }^{(14)}$ and were updated to reflect any changes in recipe content that had taken place over the years. Over $90 \%$ of schoolchildren, siblings and mothers and $76 \%$ of fathers had complete sets of three days of data collection at baseline. Mean number of available intake days at baseline were $2 \cdot 87$

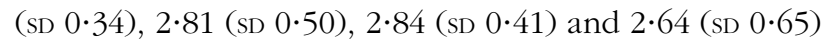
for schoolchildren, siblings, mothers and fathers, respectively. Over $90 \%$ of schoolchildren, siblings and mothers and $83 \%$ of fathers had complete sets of three days of data collection at follow-up. Mean number of available intake days at follow-up were $2 \cdot 93$ (SD 0.29), $2 \cdot 84$ (SD 0.41), $2 \cdot 86$ (SD $0 \cdot 40$ ) and 2.73 (SD 0.60 ) for schoolchildren, siblings, mothers and fathers, respectively.

\section{Nutrient intake}

We calculated the schoolchildren's daily nutrient intake from home foods, excluding the CNP snack intake. Nutrient intakes were calculated for each individual using an international food composition table adapted for use in the present study ${ }^{(16)}$. The database contains complete nutrient values for the common foods consumed in rural Kenya. Nutrient contents of less common foods were estimated from similar foods. Nutrients of interest for all household members included a measure of the quantity of food consumed, total energy and three measures of dietary quality (AS energy, total protein and AS protein).

\section{Socio-economic and demographic status of the family}

Household socio-economic status (SES) was ascertained through interviews with the lead female/male in each household. The SES questionnaire was based on the SES ranking criteria identified by the area community leaders ${ }^{(11)}$ which included possessions as well as economic and social status. A composite SES score was developed; a higher score represents a higher level of SES. Information on household members' dates of birth, ages and gender was collected as part of the household census interviews conducted with the parents. A dichotomous indicator was developed to reflect whether the schoolchild was younger or older than his/her corresponding sibling.

\section{Data analysis}

We used ANOVA to check for group-based differences in ages of various household members, household SES and household sizes. CNP snack intake was not included in the schoolchildren's daily intakes. Participants were included in their treatment group as randomized. Because the regression models handle missing data, all children, including fourteen (three from vegetarian group, three from meat group, seven from milk group and one from control group) who were lost to follow-up, were included in the analyses. If a schoolchild left the school or moved to another school with a different treatment, then his/her data after the move and those of other household members were omitted. All available data prior to the move were included in the analyses. For the nutrients of interest (total energy, AS energy, total protein and AS protein), we plotted baseline and follow-up mean nutrient intake levels. Original nutrient intake values were natural logtransformed to accommodate skewness. Schoolchildren's and siblings' data over time were analysed in a single paired longitudinal random-effects model that was fit with Restricted Maximum Likelihood estimation ${ }^{(17)}$ in the SAS mixed procedure (SAS statistical software package version 9; SAS Institute) to assess changes in intake across time and differences between groups (vegetarian, meat, milk and control). Similarly, parents' data over time were fit together in a single paired longitudinal random-effects model. Additional difference of difference assessment was conducted to assess if any nutrient intake changes were significantly different across groups. Covariates included days categorized into three categories (baseline, 
school days at follow-up and non-school days at follow-up), groups (vegetarian, meat, milk and control), sex (male, female), household member indicator (schoolchild, sibling, mother or father), schoolchild-sibling age status indicator (schoolchild younger than sibling, schoolchild older than sibling), household size and SES. A total of twenty-four schoolchildren did not have siblings, so the age status indicator variable is not defined and they were omitted from the children's analyses. Household SES information was not available for one household. Complete data were available for the remaining covariates in the analysis. As a result of these values, twenty-five schoolchildren were not included in the regression analysis. The regression model adjusts for these missing values. Separate sets of analyses were carried out for children and for parents. The schoolchild-sibling age status indicator was omitted from parents' analyses.

Our analysis followed a strategy that examined simple to more complex models that included two-way and three-way variable interactions. We first considered models with only main effects. Next, two-way interactions were created using those main effects that were significant. Significant two-way interactions were combined into three-way interactions and included. None of the three-way interactions was significant, leading to all three-way interactions being eliminated from the analysis. Our model kept all two-way interactions and associated main effects. Despite not being statistically significant, sex was included as a main effect in the final model. Significant two-way interactions were schoolchild-sibling age status $\times$ household member indicator, schoolchildsibling age status $\times$ days, schoolchild-sibling age status $\times$ group and group $\times$ days. For parents, the group $\times$ days interaction was the only significant two-way interaction. Because the household member $\times$ days interaction was found to be non-significant, a decision was made to combine schoolchildren and siblings as 'children' and to combine mothers and fathers as 'parents' in final sets of analysis and in reporting. All regression analysis adjusted for household size and SES. Our interest lies in change in nutrient intake over time and we were therefore particularly interested in the interaction between feeding group and days. The interaction captured change in the nutrient intake slope associated with each treatment group. Because days was coded as a three-group categorical variable that distinguished baseline days, followup school days and follow-up non-school days, we could compare baseline intakes with school day intakes at follow-up and with the weighted average of five school days and two non-school day average intakes at followup. School day intakes were Monday-Thursday intakes during the school year while non-school days included Sundays during the school year and Sunday to Thursday during school vacations. An $\alpha$ level of 0.05 was used to indicate statistical significance.

\section{Results}

Fifty-one and fifty-four per cent of the schoolchildren and siblings, respectively, were male. Schoolchildren's ages ranged from 6 to 11 years while that of the siblings ranged from 2 to 15 years. No significant age differences were noted between male and female schoolchildren and between male and female siblings. Mothers were significantly younger than fathers $(34 \cdot 0$ (SD 7.8) v. $41 \cdot 1$ (SD 9.7) years; Table 1 ). Between-group comparisons showed that schoolchildren in the meat group were older than children in the other groups and that they came from larger households compared with those in the milk group. There were no differences in household SES score across the snack groups.

The percentage of schoolchildren with recalls for at least one school day during the baseline period ranged from $93 \%$ among the milk group to $100 \%$ for the rest of the groups. On average, $64 \%$ of each child's baseline intake recall days ( $\sim 2$ of $3 \mathrm{~d}$ ) were carried out on school days.

Table 1 Sociodemographic characteristics of the participants by snack group*: schoolchildren and selected household members participating in the Child Nutrition Project (CNP), rural Kenya, 1998-2000

\begin{tabular}{|c|c|c|c|c|c|c|c|c|c|c|}
\hline & \multicolumn{2}{|c|}{ All } & \multicolumn{2}{|c|}{ Vegetarian } & \multicolumn{2}{|c|}{ Meat } & \multicolumn{2}{|c|}{ Milk } & \multicolumn{2}{|c|}{ Control } \\
\hline & Mean & SD & Mean & SD & Mean & SD & Mean & SD & Mean & SD \\
\hline \multicolumn{11}{|l|}{ Age (years) } \\
\hline Schoolchildren & $7 \cdot 3$ & $1 \cdot 1$ & $7 \cdot 2^{a}$ & $1 \cdot 1$ & $8 \cdot 0^{\mathrm{b}}$ & $1 \cdot 1$ & $6 \cdot 8^{a}$ & $1 \cdot 0$ & $7 \cdot 2^{a}$ & 0.9 \\
\hline Siblings & $6 \cdot 9$ & $3 \cdot 9$ & $7 \cdot \overline{1}$ & $3 \cdot 7$ & $6 \cdot 8$ & $4 \cdot 2$ & $7 \cdot 3$ & $3 \cdot 8$ & $6 \cdot 3$ & $4 \cdot 0$ \\
\hline Mothers & $34 \cdot 0$ & $7 \cdot 8$ & $35 \cdot 8$ & $8 \cdot 0$ & $35 \cdot 7$ & $7 \cdot 9$ & $32 \cdot 6$ & $7 \cdot 4$ & $31 \cdot 4$ & $7 \cdot 2$ \\
\hline Fathers & $41 \cdot 1$ & $9 \cdot 7$ & $42 \cdot 3$ & $11 \cdot 8$ & 43.5 & $7 \cdot 7$ & $39 \cdot 3$ & $9 \cdot 5$ & $39 \cdot 1$ & $9 \cdot \overline{4}$ \\
\hline Household SES (score) & $73 \cdot 2$ & $21 \cdot 6$ & $74 \cdot 1$ & $17 \cdot 1$ & $75 \cdot 5$ & $19 \cdot 3$ & $70 \cdot 1$ & $23 \cdot 0$ & 73.5 & $26 \cdot 8$ \\
\hline Household size & $6 \cdot 4$ & $2 \cdot 3$ & $6 \cdot 2^{a, b}$ & $2 \cdot 6$ & $7 \cdot 3^{a}$ & $2 \cdot 3$ & $6 \cdot 0^{\mathrm{b}}$ & $2 \cdot 3$ & $6 \cdot 2^{\mathrm{a}, \mathrm{b}}$ & $2 \cdot 0$ \\
\hline School days at baseline $(\%) \dagger$ & $64 \cdot 4$ & $15 \cdot 8$ & $69 \cdot 0$ & $14 \cdot 3$ & $64 \cdot 9$ & $11 \cdot 0$ & $60 \cdot 1$ & $21 \cdot 5$ & $64 \cdot 7$ & $15 \cdot 8$ \\
\hline School days at follow-up $(\%) \ddagger$ & $48 \cdot 8$ & $26 \cdot 3$ & $54 \cdot 4$ & $23 \cdot 5$ & $48 \cdot 5$ & $25 \cdot 1$ & $35 \cdot 2$ & $25 \cdot 6$ & $58 \cdot 3$ & $25 \cdot 4$ \\
\hline
\end{tabular}

SES, socio-economic status.

${ }^{a, b}$ Mean values within a row with unlike superscript letters were significantly different $(P<0 \cdot 05)$.

*Sample sizes given in Fig. 1.

+ School days as a percentage of intake days at baseline.

$\ddagger$ School days as a percentage of intake days at follow-up. 
Table 2 Daily nutrient intakes at baseline by snack group ${ }^{\star}+$ : schoolchildren and selected household members participating in the Child Nutrition Project (CNP), rural Kenya, 1998-2000

\begin{tabular}{|c|c|c|c|c|c|c|c|c|c|}
\hline \multirow[b]{2}{*}{ Nutrient } & \multirow[b]{2}{*}{ Household member } & \multicolumn{2}{|c|}{ Vegetarian } & \multicolumn{2}{|c|}{ Meat } & \multicolumn{2}{|c|}{ Milk } & \multicolumn{2}{|c|}{ Control } \\
\hline & & Mean & SD & Mean & SD & Mean & SD & Mean & SD \\
\hline \multirow[t]{4}{*}{ Energy (kJ) } & Schoolchildren & 6820 & 1586 & 6581 & 1858 & 6602 & 1615 & 6720 & 1854 \\
\hline & Siblings & 6402 & 2104 & 6063 & 2163 & 6489 & 1925 & 6590 & 2059 \\
\hline & Mothers & 9372 & 2632 & 8314 & 2569 & 8560 & 2577 & 9263 & 3109 \\
\hline & Fathers & 10472 & 3431 & 9962 & 3443 & 9824 & 3230 & 10376 & 3552 \\
\hline \multirow{4}{*}{ Animal-source energy (kJ) } & Schoolchildren & $355^{\mathrm{a}}$ & 247 & $157^{\mathrm{b}}$ & 137 & $326^{a}$ & 296 & $420^{\mathrm{a}}$ & 270 \\
\hline & Siblings & $379^{a}$ & 279 & $187^{\mathrm{b}}$ & 170 & $268^{a}$ & 205 & $398^{\mathrm{a}}$ & 323 \\
\hline & Mothers & $522^{\mathrm{a}}$ & 321 & $349^{b}$ & 326 & $499^{a}$ & 404 & $664^{\mathrm{a}}$ & 443 \\
\hline & Fathers & $624^{\mathrm{a}}$ & 553 & $393^{\mathrm{b}}$ & 393 & $585^{a}$ & 616 & $767^{\mathrm{a}}$ & 676 \\
\hline \multirow{4}{*}{ Protein (g) } & Schoolchildren & 50 & 12 & 50 & 17 & 48 & 14 & 53 & 14 \\
\hline & Siblings & $46^{a, b}$ & 18 & $45^{a}$ & 18 & $50^{b}$ & 16 & $49^{a, b}$ & 17 \\
\hline & Mothers & 70 & 21 & 64 & 21 & 64 & 22 & 71 & 27 \\
\hline & Fathers & 77 & 27 & 76 & 29 & 76 & 29 & 82 & 28 \\
\hline \multirow[t]{4}{*}{ Animal-source protein (g) } & Schoolchildren & $4 \cdot 8^{\mathrm{a}}$ & 3.8 & $1.9^{b}$ & $1 \cdot 65$ & $4 \cdot 1^{\mathrm{a}}$ & 3.9 & $5 \cdot 0^{a}$ & 3.5 \\
\hline & Siblings & $4 \cdot 7^{\mathrm{a}}$ & $3 \cdot 3$ & $2 \cdot 3^{b}$ & $2 \cdot 0$ & $3 \cdot 5^{\mathrm{a}}$ & $2 \cdot 9$ & $4 \cdot 7^{\mathrm{a}}$ & $4 \cdot 1$ \\
\hline & Mothers & $6 \cdot 8^{a}$ & $4 \cdot 9$ & $4 \cdot 3^{\mathrm{b}}$ & $4 \cdot 1$ & $6 \cdot 5^{\mathrm{a}}$ & $5 \cdot 7$ & $7 \cdot 9^{a}$ & $6 \cdot 0$ \\
\hline & Fathers & $8 \cdot 4^{a}$ & $8 \cdot 4$ & $5 \cdot 2^{b}$ & $6 \cdot 4$ & $8 \cdot 0^{\mathrm{a}}$ & $9 \cdot 9$ & $9 \cdot 7^{\mathrm{a}}$ & $10 \cdot 7$ \\
\hline
\end{tabular}

${ }^{a, b}$ Mean values within a row with unlike superscript letters were significantly different $(P<0 \cdot 05)$.

*Sample sizes given in Fig. 1.

tReported values are not adjusted for any covariates.

The percentage of schoolchildren with recalls for at least one school day during the follow-up period ranged from $74 \%$ among the milk group to $100 \%$ among the control group. On average, $49 \%$ of each child's baseline intake recall days (1-2 of $3 \mathrm{~d}$ ) days were carried out on school days.

\section{Baseline intake}

Schoolchildren's daily energy and protein intakes at baseline, before the school feeding programme began, were similar across the four snack groups. Siblings' daily energy intake at baseline was similar across all four snack groups (Table 2). Meat group siblings' protein intake mean estimates were significantly lower than those of siblings in the milk group. However, this difference was not sustained after adjusting for other covariates (Table 3). Meat group children had significantly lower AS energy and AS protein intakes compared with those enrolled in the vegetarian, milk and control groups (Tables 2 and 3). The differences noted in AS energy and AS protein were sustained after controlling for other covariates in the regression analysis (Table 3 ).

Parents' baseline intake estimates followed a pattern similar to that of schoolchildren: daily energy and protein intake estimates similar across all four groups and AS energy and AS protein intake estimates significantly lower among meat group parents compared with vegetarian, milk and control group parents. Group differences in AS energy and AS protein intakes at baseline were maintained even after adjusting for other covariates (Tables 3 and 4).

\section{Changes in intake at bome between baseline and follow-up}

Children in the meat group experienced significant increases in their energy and protein intakes at follow-up, with the follow-up intake values being significantly higher than those noted at baseline (Table 3). Children from the vegetarian, milk and control groups did not experience any significant changes in their energy and protein intakes at follow-up. The changes experienced by the meat group children were not significantly different from those of the control group. These results did not vary by schoolchild-sibling age status.

There was a significant decline in the vegetarian group parents' total energy and protein intakes on follow-up school days and during the overall follow-up period (Table 4). Although parents from the remaining three groups experienced some decline in their energy and protein intake values across time, the declines were not statistically significant. The vegetarian group's energy and protein intake declines were significantly different from those noted among meat and milk group parents. The declines were not significantly different from those experienced by the control group parents.

Meat and control group parents experienced significant declines in AS energy and AS protein on follow-up school days and the overall follow-up period, while the vegetarian group parents experienced a significant decline in AS protein intake during the overall follow-up period. Milk group parents experienced only slight non-significant declines in dietary quality measures across time. Meat and control group dietary quality declines were significantly different from those noted among the milk group parents. No other differences were noted across groups.

\section{Discussion}

These findings allow an evaluation of the changes in household members' intakes over the two years of the 
Table 3 Children's log-transformed daily nutrient intakes (baseline and follow-up period) and change estimates by snack group* $¥ \ddagger$, Child Nutrition Project (CNP), rural Kenya, 1998-2000

\begin{tabular}{|c|c|c|c|c|c|c|c|c|c|c|}
\hline & \multirow{2}{*}{\multicolumn{2}{|c|}{$\frac{\text { Baseline }}{\text { Intake }}$}} & \multicolumn{4}{|c|}{ School days at follow-up } & \multicolumn{4}{|c|}{ Follow-up§ } \\
\hline & & & \multicolumn{2}{|c|}{ Intake } & \multicolumn{2}{|c|}{ Change from baseline } & \multicolumn{2}{|c|}{ Intake } & \multicolumn{2}{|c|}{ Change from baseline } \\
\hline & Mean & SE & Mean & SE & Mean & SE & Mean & SE & Mean & SE \\
\hline \multicolumn{11}{|l|}{ Total energy } \\
\hline Vegetarian & $7 \cdot 26$ & 0.04 & $7 \cdot 20$ & 0.05 & -0.06 & 0.06 & $7 \cdot 20$ & 0.05 & -0.05 & 0.05 \\
\hline Meat & $7 \cdot 23$ & 0.04 & $7 \cdot 28$ & 0.05 & 0.05 & 0.06 & $7 \cdot 32 \|$ & 0.04 & $0.09 \|$ & 0.05 \\
\hline Milk & $7 \cdot 28$ & 0.04 & $7 \cdot 29$ & 0.06 & 0.01 & 0.06 & $7 \cdot 29$ & 0.04 & 0.02 & 0.05 \\
\hline Control & $7 \cdot 33$ & 0.05 & $7 \cdot 39$ & 0.06 & 0.07 & 0.06 & $7 \cdot 37$ & 0.05 & 0.04 & 0.06 \\
\hline \multicolumn{11}{|l|}{ Total protein } \\
\hline Vegetarian & $3 \cdot 80$ & 0.05 & $3 \cdot 78$ & 0.06 & -0.02 & 0.07 & $3 \cdot 75$ & 0.05 & -0.05 & 0.06 \\
\hline Meat & $3 \cdot 80$ & 0.04 & $3 \cdot 89$ & 0.06 & 0.09 & 0.06 & $3 \cdot 93 \|$ & 0.05 & $0 \cdot 14 \|$ & 0.05 \\
\hline Milk & 3.85 & 0.04 & 3.90 & 0.06 & 0.05 & 0.07 & $3 \cdot 88$ & 0.05 & 0.03 & 0.06 \\
\hline Control & 3.92 & 0.05 & $3 \cdot 94$ & 0.06 & 0.02 & 0.07 & $3 \cdot 93$ & 0.05 & 0.02 & 0.06 \\
\hline \multicolumn{11}{|c|}{ Animal-source energy } \\
\hline Vegetarian & $4 \cdot 14^{\mathrm{a}}$ & $0 \cdot 10$ & $3 \cdot 96$ & $0 \cdot 13$ & $-0 \cdot 19$ & $0 \cdot 13$ & $4 \cdot 02$ & $0 \cdot 11$ & $-0 \cdot 15$ & $0 \cdot 12$ \\
\hline Meat & $3 \cdot 63^{\mathrm{b}}$ & 0.09 & $3 \cdot 32$ & $0 \cdot 12$ & $-0 \cdot 31$ & $0 \cdot 13$ & $3 \cdot 46$ & $0 \cdot 10$ & $-0 \cdot 19$ & $0 \cdot 11$ \\
\hline Milk & $4 \cdot 05^{\mathrm{a}}$ & 0.09 & $4 \cdot 05$ & $0 \cdot 13$ & -0.001 & $0 \cdot 14$ & $4 \cdot 06$ & $0 \cdot 11$ & -0.004 & $0 \cdot 11$ \\
\hline Control & $4 \cdot 29^{\mathrm{a}}$ & $0 \cdot 12$ & $3 \cdot 81$ & $0 \cdot 14$ & -0.47 & $0 \cdot 14$ & $3 \cdot 92$ & $0 \cdot 12$ & -0.39 & 0.12 \\
\hline \multicolumn{11}{|c|}{ Animal-source protein } \\
\hline Vegetarian & $1 \cdot 50^{\mathrm{a}}$ & 0.08 & $1 \cdot 31$ & $0 \cdot 10$ & -0.19 & $0 \cdot 10$ & $1 \cdot 37$ & 0.08 & -0.15 & 0.09 \\
\hline Meat & $1 \cdot 10^{\mathrm{b}}$ & 0.07 & 0.90 & $0 \cdot 10$ & $-0 \cdot 21$ & $0 \cdot 10$ & $1 \cdot 00$ & 0.08 & -0.13 & 0.08 \\
\hline Milk & $1 \cdot 43^{\mathrm{a}}$ & 0.07 & $1 \cdot 50$ & $0 \cdot 10$ & $0.07 \%$ & $0 \cdot 10$ & $1 \cdot 49$ & 0.08 & 0.05 & 0.08 \\
\hline Control & $1 \cdot 58^{\mathrm{a}}$ & 0.09 & $1 \cdot 27$ & $0 \cdot 11$ & $-0 \cdot 31$ & $0 \cdot 11$ & $1 \cdot 36$ & 0.09 & -0.23 & 0.09 \\
\hline
\end{tabular}

${ }^{a, b}$ For each nutrient, mean values within a column with unlike superscript letters were significantly different $(P<0 \cdot 05)$.

*Sample sizes: $n 37$ for vegetarian group; $n 47$ for meat group; $n 45$ for milk group; $n 29$ for control group.

tResults are estimates from regression analyses on natural log-transformed nutrient intake values.

$\ddagger$ Analysis adjusted for schoolchild-sibling age status, household socio-economic status, household size and sex

$\S$ Weighted average of school and non-school days at follow-up.

॥Significantly different from baseline $(P<0.05)$.

$\uparrow$ Change significantly different from that of the control group $(P<0.05)$.

Table 4 Parents' log-transformed daily nutrient intakes (baseline and follow-up period) and change estimates by snack group* $+\ddagger$, Child Nutrition Project (CNP), rural Kenya, 1998-2000

\begin{tabular}{|c|c|c|c|c|c|c|c|c|c|c|}
\hline & \multirow{2}{*}{\multicolumn{2}{|c|}{$\begin{array}{c}\text { Baseline } \\
\text { Intake }\end{array}$}} & \multicolumn{4}{|c|}{ School days at follow-up } & \multicolumn{4}{|c|}{ Follow-up§ } \\
\hline & & & \multicolumn{2}{|c|}{ Intake } & \multicolumn{2}{|c|}{ Change from baseline } & \multicolumn{2}{|c|}{ Intake } & \multicolumn{2}{|c|}{ Change from baselin } \\
\hline & Mean & SE & Mean & SE & Mean & SE & Mean & SE & Mean & SE \\
\hline \multicolumn{11}{|l|}{ Total energy } \\
\hline Vegetarian & $7 \cdot 67$ & 0.05 & $7 \cdot 42 \|$ & 0.06 & $-0 \cdot 24$ & 0.07 & $7 \cdot 43 \|$ & 0.05 & -0.23 & 0.06 \\
\hline Meat & $7 \cdot 58$ & 0.04 & $7 \cdot 55$ & 0.06 & -0.02 & 0.06 & $7 \cdot 59$ & 0.05 & 0.01 & 0.05 \\
\hline Milk & $7 \cdot 63$ & 0.04 & $7 \cdot 56$ & 0.06 & -0.08 & 0.07 & $7 \cdot 57$ & 0.05 & -0.08 & 0.05 \\
\hline Control & $7 \cdot 62$ & 0.05 & $7 \cdot 51$ & 0.07 & $-0 \cdot 11$ & 0.07 & $7 \cdot 53$ & 0.06 & -0.09 & 0.06 \\
\hline \multicolumn{11}{|l|}{ Total protein } \\
\hline Vegetarian & $4 \cdot 20$ & 0.05 & $3 \cdot 98 \|$ & 0.07 & -0.22 & 0.07 & $3 \cdot 97 \|$ & 0.06 & -0.23 & 0.06 \\
\hline Meat & $4 \cdot 15$ & 0.04 & $4 \cdot 13$ & 0.07 & -0.01 & 0.07 & $4 \cdot 17$ & 0.05 & 0.02 & 0.06 \\
\hline Milk & $4 \cdot 19$ & 0.05 & $4 \cdot 14$ & 0.07 & -0.05 & 0.08 & $4 \cdot 14$ & 0.05 & -0.05 & 0.06 \\
\hline Control & $4 \cdot 21$ & 0.06 & $4 \cdot 06$ & 0.07 & $-0 \cdot 15$ & 0.07 & 4.09 & 0.06 & $-0 \cdot 12$ & 0.07 \\
\hline \multicolumn{11}{|c|}{ Animal-source energy } \\
\hline Vegetarian & $4 \cdot 59^{\mathrm{a}}$ & $0 \cdot 11$ & $4 \cdot 42$ & $0 \cdot 14$ & $-0 \cdot 16$ & $0 \cdot 14$ & $4 \cdot 38$ & $0 \cdot 12$ & $-0 \cdot 21$ & $0 \cdot 12$ \\
\hline Meat & $4 \cdot 05^{\mathrm{b}}$ & $0 \cdot 10$ & $3 \cdot 57 \|$ & $0 \cdot 13$ & -0.51 & $0 \cdot 14$ & $3 \cdot 79 \|$ & $0 \cdot 11$ & -0.36 & $0 \cdot 11$ \\
\hline Milk & $4 \cdot 49^{\mathrm{a}}$ & 0.09 & $4 \cdot 44$ & 0.14 & -0.07 & 0.14 & $4 \cdot 48$ & $0 \cdot 11$ & -0.01 & $0 \cdot 11$ \\
\hline Control & $4 \cdot 68^{\mathrm{a}}$ & $0 \cdot 12$ & $4 \cdot 20 \|$ & $0 \cdot 15$ & -0.50 & 0.13 & $4 \cdot 22 \|$ & 0.13 & -0.46 & $0 \cdot 13$ \\
\hline \multicolumn{11}{|c|}{ Animal-source protein } \\
\hline Vegetarian & $1 \cdot 87^{\mathrm{a}}$ & 0.08 & $1 \cdot 70$ & $0 \cdot 10$ & -0.17 & $0 \cdot 11$ & $1 \cdot 67 \|$ & 0.09 & -0.20 & 0.09 \\
\hline Meat & $1 \cdot 44^{\mathrm{b}}$ & 0.08 & $1 \cdot 05 \|$ & $0 \cdot 10$ & -0.39 & $0 \cdot 10$ & $1 \cdot 17 \|$ & 0.09 & -0.27 & 0.09 \\
\hline Milk & $1 \cdot 81^{\mathrm{a}}$ & 0.07 & $1 \cdot 78$ & $0 \cdot 11$ & -0.03 & $0 \cdot 11$ & 1.82 & 0.09 & 0.01 & 0.09 \\
\hline Control & $1.92^{\mathrm{a}}$ & 0.09 & $1 \cdot 58 \|$ & $0 \cdot 11$ & $-0 \cdot 34$ & 0.12 & $1 \cdot 60 \|$ & $0 \cdot 10$ & -0.32 & $0 \cdot 10$ \\
\hline
\end{tabular}

${ }^{\mathrm{a}, \mathrm{b}}$ For each nutrient, mean values within a column with unlike superscript letters were significantly different $(P<0 \cdot 05)$.

*Sample sizes given in Fig. 1.

tResults are estimates from regression analyses on natural log-transformed nutrient intake values.

$\ddagger$ Analysis adjusted for household socio-economic status, household size and sex.

$\S$ Weighted average of school and non-school days at follow-up.

॥Significantly different from baseline $(P<0.05)$.

- Change significantly different from that of the control group $(P<0.05)$. 
CNP feeding study. Changes in the food consumed at home (excluding the school snack for the schoolchild) differed by household member (parent $v$. child) and by treatment group. Changes associated with total protein exhibited similar patterns to those noted for total energy, an indication that total protein may be more of a measure of food quantity and not quality for this population group in rural Kenya. Changes associated with AS protein exhibited similar patterns to those noted for AS energy.

The study's results support our first hypothesis: the home-based energy, protein, AS energy and AS protein intakes of snack-receiving schoolchildren did not decrease across the study period. Siblings experienced changes that were similar to those of schoolchildren, thus lending support to our second hypothesis to a large extent. Despite the regression analysis showing no significant differences in children's energy and protein intakes at baseline (Table 3), the meat group children's energy and protein intakes increased during the study period. A possible explanation for these increases may lie in meat group schoolchildren's increased appetite as a result of improved $\mathrm{Zn}$ intake from the meat-containing snacks ${ }^{(18)}$. This increase may also be as a result of increased muscle growth associated with the meat-receiving schoolchildren ${ }^{(19)}$. However, this does not explain the similar energy and protein intake increases noted among the group's siblings. It is possible that the schoolchildren's increased intake may have had a residual effect on overall children's intake in the respective households. However our data do not allow us to assess such a hypothesis. Control group children did not experience any significant change in energy, protein, AS energy or AS protein intake across time, clearly showing support for our third hypothesis with respect to children's diet quantity and quality.

However, the study results showed minimal support for the second and third hypotheses with respect to parent's intakes. There was a general decline among parents' energy and protein and AS energy and AS protein intakes indicating a decline in food quantity and quality. This decline may have been as a result of crop failure associated with failed 'long rains' between March and May $2000^{(20)}$. However, as noted within the Results section, the declines were significant only for vegetarian, meat and control group parents but not for the milk group, indicating that the magnitude of food quantity and quality decline was different among parents. Such differences in response were not anticipated and more research into the possible reasons is needed.

These results demonstrate that irrespective of whether the schoolchildren received snacks at school or not, the children's home-based dietary intake seemed to have been given priority and protected from any significant decline over time. On the other hand, most parents did not receive similar protection and experienced declines in their dietary quantity and quality over time, suggesting that there may be differences in ways that households and their members respond to changes in food amounts and food quality, especially in times of food scarcity. These differences may need to be further assessed. Even though children's homebased intake appear to be protected during times of food scarcity, feeding programmes such as the CNP are important in addressing inadequacies that are present in recipients' diets and physical growth status. Analysis of CNP's schoolchildren's nutritional status reported inadequate dietary intake and physical growth at baseline ${ }^{(15,19)}$.

\section{Strengths and limitations of the study}

One strength of the present study lies in the use of dietary data collected multiple times (three days at baseline and three days at follow-up), providing an approximation of usual intakes among the household members. The use of the $24 \mathrm{~h}$ recall has been shown to be appropriate in this population ${ }^{(21,22)}$. Although the weighment method is considered a better estimate for dietary intake, its use is limited in large studies due to the costs involved. Weighed records may also result in study participants altering their dietary behaviour, especially if enumerators are present. Another limitation lies in including only one of three schools in each of the study groups. We would like to note that although the randomization process generally resulted in comparable measures at baseline (Table 1), the meat group schoolchildren were slightly older and they came from significantly larger households, which may explain their lower intakes of AS energy and protein at baseline. Larger household sizes place a strain on limited household resources resulting in relatively lower food intake levels among household members ${ }^{(23)}$. Additionally, older children may receive relatively lower amounts of food compared with younger children in times of food scarcity. An assessment among Indian schoolchildren reported that being an older target recipient, larger household size and poorer household were significantly associated with higher transfer of energy from the school meal recipient ${ }^{(9)}$. Our analyses adjusted for important factors that have been shown to influence dietary intake: schoolchild-sibling age indicator, sex, SES and household size. Thus, the reported impact is independent of the children's age and sex and household SES and size.

\section{Conclusions}

Results from this analysis indicate a number of factors that may be useful in planning for supplementary feeding interventions in Kenya and similar communities. There was no evidence that schoolchildren who received supplementary snacks at school experienced reduced intakes at home or that intakes by other family members were increased at the expense of the schoolchild's intake. Even when excluding the nutrient contributions from the school snack, children were generally protected from a decline in nutrient intake levels compared with adult members of the family. 


\section{Acknowledgements}

Preliminary results of these analyses were presented at the Federation of American Societies for Experimental Biology (FASEB) conference, New Orleans, USA, 18-22 April 2009 (presentation title: Impact of supplementary feeding on intra-household food distribution in rural Kenya). This work was carried out as part of the CNP study, which was supported by the Global Livestock Collaborative Research Support Program, University of California at Davis, through the US Agency for International Development (grant number PCE-G-00-98-00036-00). There are no conflicts of interest. C.A.G. was the Field Nutritionist for CNP, conducted the research, performed the statistical analysis and wrote the paper. S.P.M. was the Co-Investigator for CNP, conducted the research, helped guide the statistical analysis and wrote the paper. R.E.W. provided guidance on the statistical analysis and edited numerous drafts. C.G.N. was the Principal Investigator for $\mathrm{CNP}$, was responsible for the study design, oversaw overall research activities, and helped guide the statistical analysis and writing of the manuscript. All authors read and approved the final manuscript. The authors would like to thank all participants and workers for their collaboration in the CNP.

\section{References}

1. Haddad L, Pena C, Nishida C et al. (1996) Food Security and Nutrition Implications of Intrabousebold Bias: A Review of Literature. Washington, DC: International Food Policy Research Institute.

2. Kramer EM, Peterson KE, Rogers BL et al. (1997) Intrahousehold allocation of energy intake among children under five years and their parents in rural Bangladesh. Eur J Clin Nutr 51, 750-756.

3. Luo W, Zhai F, Jin S et al. (2001) Intrahousehold food distribution: a case study of eight provinces in China. Asia Pac J Clin Nutr 10, Suppl., S19-S28.

4. Sudo N, Sekiyama M, Maharjan M et al. (2006) Gender differences in dietary intake among adults of Hindu communities in lowland Nepal: assessment of portion sizes and food consumption frequencies. Eur J Clin Nutr 60, 469-477.

5. Engle PL \& Nieves I (1993) Intra-household food distribution among Guatemalan families in a supplementary feeding program: behavior patterns. Soc Sci Med 36, 1605-1612.

6. Adelman SW, Gilligan DO \& Lehrer K (2008) How Effective are Food for Education Programs? A Critical Assessment of Evidence from Developing Countries. Washington DC: International Food Policy and Research Institute; available at http://www.ifpri.org/sites/default/files/pubs/pubs/fpreview/ pv09/pv09.pdf

7. Jacoby HG (2002) Is there an intrahousehold 'flypaper effect? Evidence from a school feeding programme. Econ J 112, 196-221.

8. Ahmed AU (2004) Impact of Feeding Children in School: Evidence from Bangladesh. Washington, DC: International Food Policy and Research Institute.
9. Afridi F (2005) Public Transfers and Intra-Household Resource Allocation: Evidence from a Supplementary School Feeding Program. Ann Arbor, MI: University of Michigan ; available at http://www.fordschool.umich.edu/ edts/pdfs/afridi_paper.pdf

10. Kazianga H, de Walque D, Alderman H (2009) Educational and Health Impacts of Two School Feeding Schemes: Evidence from Randomized Trial in Rural Burkina Faso. Impact Evaluation Series no. 30, Policy Research Working Paper no. 4976. Washington, DC: The World Bank Development Research Group; available at http://www-wds. worldbank.org/external/default/WDSContentServer/IW3P/ IB/2009/07/15/000158349_20090715163511/Rendered/PDF/ WPS4976.pdf

11. Neumann CG, Bwibo NO, Murphy SP et al. (2003) Animal source foods improve dietary quality, micronutrient status, growth and cognitive function in Kenyan school children: background, study design and baseline findings. $J$ Nutr 133, 11 Suppl. 2, 3941S-3949S.

12. Mukudi EO, Neumann C \& Bwibo NO (2011) Effects of a school feeding intervention on school attendance rates among elementary school children in rural Kenya. Nutrition 27, 188-193.

13. Gewa C, Murphy SP, Bwibo NO et al. (2005) Assessment of Snack Acceptance During a School Feeding Intervention in Rural Kenya. Global Livestock CRSP Research Brief no. 05-03-CNP. Davis, CA: Global Livestock Collaborative Research Support Program.

14. Neumann C, Bwibo NO \& Sigman M (1987) Diet Quantity and Quality. Functional Effects on Rural Kenyan Families. Kenya Project Final Report. Phase II - 1989-1992. Human Nutrition Collaborative Research Support Program. Los Angeles, CA: UCLA School of Public Health.

15. Murphy SP, Gewa C, Liang L et al. (2003) School snacks containing animal source foods improve dietary quality for children in rural Kenya. J Nutr 133, 11 Suppl. 2, 3950S-3956S.

16. Calloway DH, Murphy SP, Bunch S et al. (2004) World Food Dietary Assessment System User's Guides. Berkley, CA: University of California.

17. Weiss RE (2005) Modeling Longitudinal Data. New York: Springer.

18. Prasad AS (1991) Discovery of human zinc deficiency and studies in an experimental human model. Am J Clin Nutr 53, 403-412.

19. Grillenberger M, Neumann CG, Murphy SP et al. (2003) Food supplements have a positive impact on weight gain and the addition of animal source foods increases lean body mass of Kenyan school children. J Nutr 133, 11 Suppl. 2, 3957S-3964S.

20. Food and Agriculture Organization of the United Nations (2000) Special Report: Crop and Food Supply Situation in Kenya. Rome: FAO; available at http://www.fao.org/ docrep/004/x7697e/x7697e00.htm

21. Kigutha HN (1997) Assessment of dietary intake in rural communities in Africa: experiences in Kenya. Am J Clin Nutr 65, 4 Suppl., 1168S-1172S.

22. Gewa CA, Murphy SP \& Neumann CG (2009) A comparison of weighed and recalled intakes for schoolchildren and mothers in rural Kenya. Public Health Nutr 12, 1197-1204.

23. Pelto GH, Urgello J, Allen NH et al. (1991) Household size, food intake and anthropometric status of school-age children in a highland Mexican area. Soc Sci Med 33, $1135-1140$. 